Jin $\mathrm{Li}^{*}$ and Hongzhou Ma

\title{
Zinc and lead recovery from jarosite residues produced in zinc hydrometallurgy by vacuum reduction and distillation
}

https://doi.org/10.1515/gps-2017-0079

Received May 19, 2017; accepted August 30, 2017; previously published online September 26, 2017

Abstract: Jarosite residues in zinc hydrometallurgy are considered as hazardous waste as they contain heavy metals such as $\mathrm{Zn}$ and $\mathrm{Pb}$. A novel vacuum reduction and distillation process has been put forward to recover $\mathrm{Zn}$ and $\mathrm{Pb}$ from jarosite residues. Four main factors including the amount of coke powder, amount of lime powder, heating temperature, and holding time which have an influence on volatilization of $\mathrm{Zn}$ and $\mathrm{Pb}$ were studied in this paper by the statistical software JMP. The results show that heating temperature is the key factor among the four contributing factors. By examination of the relationship between the four factors and the volatilization of $\mathrm{Zn}$ and $\mathrm{Pb}$, it is indicated that a heating temperature of $1000^{\circ} \mathrm{C}$, holding time of $90 \mathrm{~min}$, and addition of $29.6 \%$ coke powder and $13 \%$ lime powder to the residues led to optimum ratios of $99.4 \%$ of both $\mathrm{Zn}$ and $\mathrm{Pb}$ volatilization. The results show that this process is an effective method in dealing with zinc, lead, and iron in jarosite residues and it is an environment-friendly process.

Keywords: jarosite residues; lead; reduction; volatilization; zinc.

\section{Introduction}

Jarosite residues come from jarosite process in traditional zinc hydrometallurgy [1,2]. When zinc calcine is leached with strong acid at high temperature a leaching solution with high iron is produced. More calcine is added to neutralize the solution and remove iron, thereby a precipitation of jarosite is formed [2, 3]. Zinc hydrometallurgy provides for more than $85 \%$ weight of

*Corresponding author: Jin Li, School of Metallurgical Engineering, Xi'an University of Architecture and Technology, Xi'an 710055, P.R. China, e-mail: lijinjeanny@126.com

Hongzhou Ma: School of Metallurgical Engineering, Xi'an University of Architecture and Technology, Xi'an 710055, P.R. China zinc in the world every year [2]. In China, approximately one million tons of jarosite residues are produced annually [1]. Accumulated jarosite residues have to be stored and thus take up massive land area. Furthermore, jarosite residues are considered as hazardous wastes and create some environmental problems due to the presence of heavy metals such as lead $(\mathrm{Pb})$, zinc $(\mathrm{Zn})$, indium (In), silver (Ag), etc., and some toxic ingredients such as arsenic (As) [4].

Many efforts have been made to treat jarosite residues. It is important to recover valuable metals from the residues. Till now, three main kinds of methods have been adopted to recover valuable metals. The first method is the reduction volatilization. Rotary kiln process in China is one such method. In this process, coke powder is added to the residues and then the mixture is heated to $1200^{\circ} \mathrm{C}$ to volatilize zinc and lead and recover these two metals. The process is effective but the energy consumption is high. Furthermore, the volatilization process results in air pollution [3-5]. The running Ausmelt in South Korea is of high cost and causes air pollution [2, 4]. In another direct reduction process, jarosite residues are reduced with coal slime. A good volatilization of $\mathrm{Zn}$ and $\mathrm{Pb}$ is achieved and a high recovery of iron is obtained in this process but sulfur in the residues is a contamination to the obtained iron [6]. Therefore, a good reduction volatilization method should be a comprehensive recovery method. The second method is roasted jarosite residues leaching process in which the residues are roasted to decompose the stable valuable metal forms and subsequently leached to recover the valuable metals. If $\mathrm{NH}_{4} \mathrm{Cl}$ solution is used as the leaching agent, many metals such as $\mathrm{Pb}, \mathrm{Zn}$, and $\mathrm{Ag}$ can be leached and recovered $[1,2,4]$, but a residue with approximately $55 \%$ iron is left $[4,7,8]$. The third method is the direct acid leaching process in which jarosite residues are leached with acid again to recover zinc and iron $[9,10]$. This kind of method has a very complicated impurity removing process making it costly [9-11]. As stated earlier, the problem in the recovery of valuable metals from jarosite residues is to find a comprehensive way to recover as many metals as possible at low cost and low pollution.

A novel vacuum reduction and distillation process was employed in this study to recover zinc and lead as well 
as to recover iron by magnetic separation from jarosite residues. In this process, jarosite residues were mixed with coke and lime powder and heated to reduce zinc and lead and then distill the metals in a vacuum furnace. As a result, zinc and lead were reduced and recovered by distillation while iron was reduced to magnetite or/and iron element thereby being able to be separated by magnetism. The results show that this method is effective. The experimental conditions which may have an effect on the volatilization process have been discussed in this paper.

\section{Materials and methods}

\subsection{Materials}

Jarosite residues used in this study were taken from a zinc smelter in Shaanxi province in China. Chemical and phase analyses of the residues were carried out after they had been dried at $100^{\circ} \mathrm{C}$. Contents of some metals in the residues are given in Table 1 and the XRD patterns are shown in Figure 1.

It is seen in Figure 1 that the main phases in the residues are iron hydroxide, zinc hydroxide, goethite, and jarosite. By examination of the zinc calcine leaching process in zinc metallurgy, lead in the residues is thought to exist as lead sulfate [4].

Coke powder (Shaanxi Longmen Steel, China) with particle size less than $76 \mu \mathrm{m}$ was added to the residues as reducing agent. Available lime powder produced by Tianjin health chemical reagent factory

Table 1: Content of some metals in jarosite residues (wt\%).

\begin{tabular}{lccr}
\hline Metal & Pb & Zn & Fe \\
\hline Content & 3.0 & 5.55 & 25.61 \\
\hline
\end{tabular}

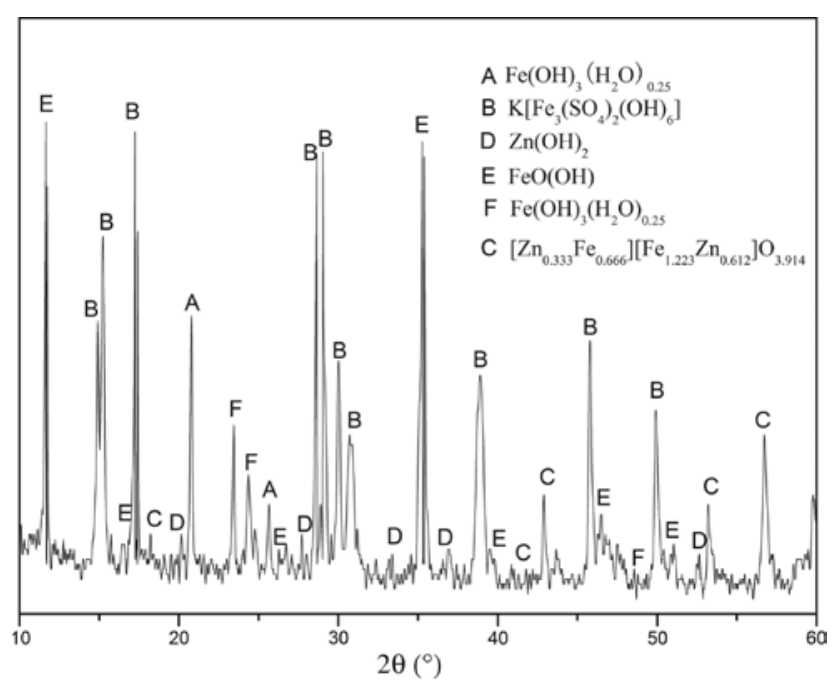

Figure 1: XRD pattern of jarosite residues. was used to decrease the partial pressure of $\mathrm{SO}_{2}$ released during the process and increase the melting temperature of jarosite residues [4].

\subsection{Theoretical analysis of the experiment}

According to some research, the main phases in jarosite residues will change to other chemical forms when they are heated at the temperature determined by this vacuum reduction distillation process. Jarosite decomposes into $\mathrm{Fe}_{2} \mathrm{O}_{3}, \mathrm{SO}_{2}$, and $\mathrm{H}_{2} \mathrm{O}[1,3,12]$. Iron hydroxide changes into $\mathrm{Fe}_{2} \mathrm{O}_{3}$ and $\mathrm{H}_{2} \mathrm{O}$ [13]. Zinc hydroxide changes into $\mathrm{ZnO}$ and $\mathrm{H}_{2} \mathrm{O}$ [12]. Lead sulfate decomposes into $\mathrm{PbO}$ and $\mathrm{SO}_{2}$. After the decomposition, during the reduction process $\mathrm{ZnO}$ and $\mathrm{PbO}$ are reduced by carbon producing elemental zinc and lead while $\mathrm{Fe}_{2} \mathrm{O}_{3}$ is reduced to the magnetic phases of iron, i.e. $\mathrm{Fe}$ and/or $\mathrm{Fe}_{3} \mathrm{O}_{4}$. Subsequently, zinc and lead are distillated in the vacuum furnace and then recovered. The added lime powder reacts with $\mathrm{SO}_{2}$ emitted during the heating process forming calcium sulfate. This decreases the partial pressure of $\mathrm{SO}_{2}$ favoring the reduction reactions of iron and lead. The vacuum in the furnace can not only accelerate the distillation process but also prevent the reduced metals from being oxidized.

\subsection{Experimental procedure}

The dried residues were thoroughly mixed with coke and lime powder in a determined proportion. The mixture then was pressed into columns (diameter: $20 \mathrm{~mm}$, height: $10 \mathrm{~mm}$ ) under a pressure of 5.5 MPa. The prepared sample was transferred into a vacuum furnace (Luoyang Sigma Instrument Manufacture Co., Ltd., Luoyang, China) and then heated to a preset temperature for a given holding time under the vacuum of 2-4 Pa. After furnace cooling, the content of $\mathrm{Zn}$ and $\mathrm{Pb}$ in each sample was tested and the volatilization ratio of each metal was calculated, respectively.

\section{Results and discussion}

\subsection{Approach for experiment design and data processing}

The experiment was designed using DOE (design of experiment) function of JMP $[14,15]$ which is a statistical software developed by the SAS Institute Inc, Cary, NC, USA. The four contributing factors including the amount of coke powder, amount of lime powder added to the residues, heating temperature, and holding time which may have a great influence on the volatilization were studied using JMP. Due to the interfering tasks of volatilization of both $\mathrm{Zn}$ and $\mathrm{Pb}$ in this vacuum reduction and distillation process, the results of the experiment were analyzed using leverage diagram of JMP to determine the significance of the influence of each factor on the volatilization. This data processing method had been selected by reading the JMP software manual. 


\subsection{Results}

Each sample weighed about $40 \mathrm{~g}$ in which the amount of coke powder varied from $10 \%$ to $50 \%$ and the amount of lime powder ranged from $1 \%$ to $25 \%$. The heating temperatures changed from $800^{\circ} \mathrm{C}$ to $1000^{\circ} \mathrm{C}$ and the holding times varied from $30 \mathrm{~min}$ to $90 \mathrm{~min}$. For each sample in each test, the four contributing factors of the experimental conditions were determined according to the design of JMP.

Table 2: Experimental conditions and the relevant volatilization ratio results of $\mathrm{Zn}$ and $\mathrm{Pb}$ in jarosite residues.

\begin{tabular}{|c|c|c|c|c|c|c|}
\hline Sample no. & Coal powder (\%) & Lime powder (\%) & Heating temperature $\left({ }^{\circ} \mathrm{C}\right)$ & Holding time (min) & $R_{\mathrm{zn}}(\%)$ & $R_{\mathrm{Pb}}(\%)$ \\
\hline 1 & 30 & 13 & 900 & 60 & 76.5 & 97.8 \\
\hline 2 & 50 & 13 & 800 & 60 & 14.6 & 42.3 \\
\hline 3 & 10 & 1 & 1000 & 60 & 83.2 & 99 \\
\hline 4 & 10 & 13 & 800 & 90 & 0 & 13 \\
\hline 5 & 30 & 25 & 800 & 90 & 2.1 & 0 \\
\hline 6 & 50 & 1 & 1000 & 30 & 34.7 & 93.5 \\
\hline 7 & 10 & 25 & 1000 & 30 & 64.13 & 99.3 \\
\hline 8 & 50 & 1 & 900 & 90 & 33.8 & 62.6 \\
\hline 9 & 10 & 1 & 900 & 30 & 7.3 & 63.6 \\
\hline 10 & 50 & 25 & 900 & 30 & 8 & 18.8 \\
\hline 11 & 30 & 1 & 800 & 60 & 4.68 & 60.5 \\
\hline 12 & 10 & 25 & 900 & 90 & 36.2 & 97.3 \\
\hline 13 & 50 & 25 & 1000 & 60 & 99.7 & 98.3 \\
\hline 14 & 10 & 25 & 800 & 30 & 14.1 & 37 \\
\hline 15 & 30 & 13 & 1000 & 90 & 99.4 & 99.4 \\
\hline
\end{tabular}

$R_{\mathrm{zn}}$ and $R_{\mathrm{Pb}}$, in Table 2, stand for the volatilization ratios of zinc and lead, respectively.
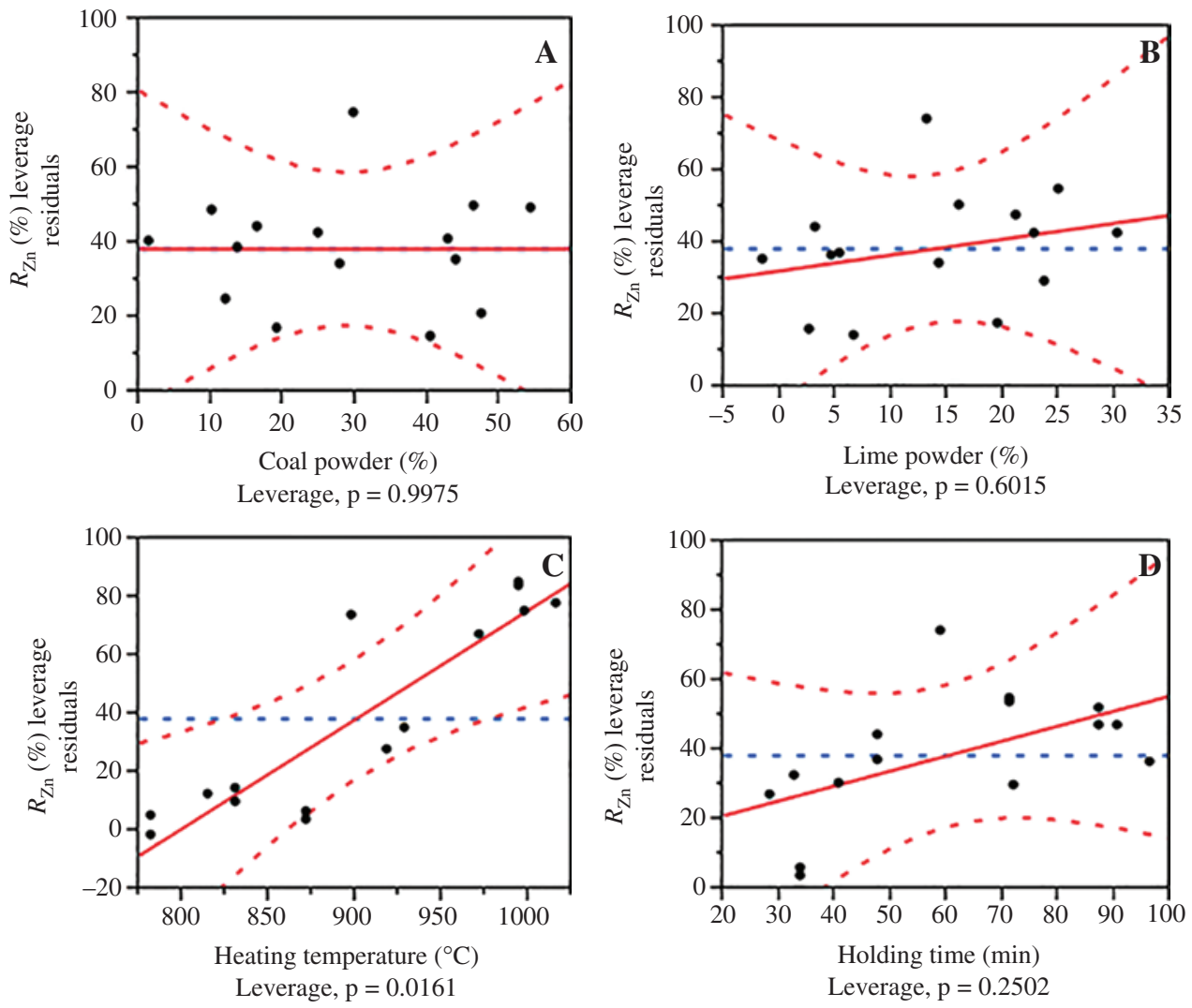

Figure 2: Leverage of the four factors for zinc volatilization. 
The reduced solid samples appeared as powder and were not sintered making the following magnetic separation easier. It is reported that the magnetic separation is used to recover zinc and iron in jarosite residues [16]. Zinc ferrite in the residues is reduced to zinc oxide and magnetic iron or iron oxide. Thus, iron can be separated by magnesium. However, the agglomeration of the residues in the roasting process leads the separation to a bad result [16]. The experimental conditions and the corresponding volatilization results of zinc and lead are shown in Table 2.

The leverage diagram of JMP, which is intuitive and convenient was used to find the significance of the impact of each factor. The volatilization ratio data in Table 2 were input into the software making the leverage diagrams being drown. Figures 2 and 3 show the leverage diagrams of the four factors for zinc and lead volatilization, respectively.

\subsection{Discussion}

\subsubsection{Significance of influence of the four contributing factors on the volatilization}

The dotted horizontal line in Figure 2B represents the mean of zinc volatilization ratios of the 15 specimens in Table 2 and the diagonal line is its relevant least square fitting line given by JMP. The two dotted curves in Figure 2B mark out the confidence interval with 95\% probability. Furthermore, the similar lines and curves in the other leverage diagrams in Figures 2 and 3 have similar meaning. It is seen that there is only one line in Figure 2A. This is because the fitting line coincides with the mean line.

From the JMP manual it is known that in each leverage diagram if the mean line and the curves intersected this indicates that there is a significant correlation between the contributing factor and the volatilization ratio. Such intersections can be found in Figures $2 \mathrm{C}$ and $3 \mathrm{C}$ showing the significance of the influence of heating temperature on the volatilization ratios of both zinc and lead. On the other hand, this also implies that changes in the other three factors have an unobvious impact on the process in the experiment.

\subsubsection{Influence of the four contributing factors on zinc and lead volatilization}

Figure 4 shows the relationship between volatilization ratios and each contributing factor which is calculated from least square regression. The diagonal line in each
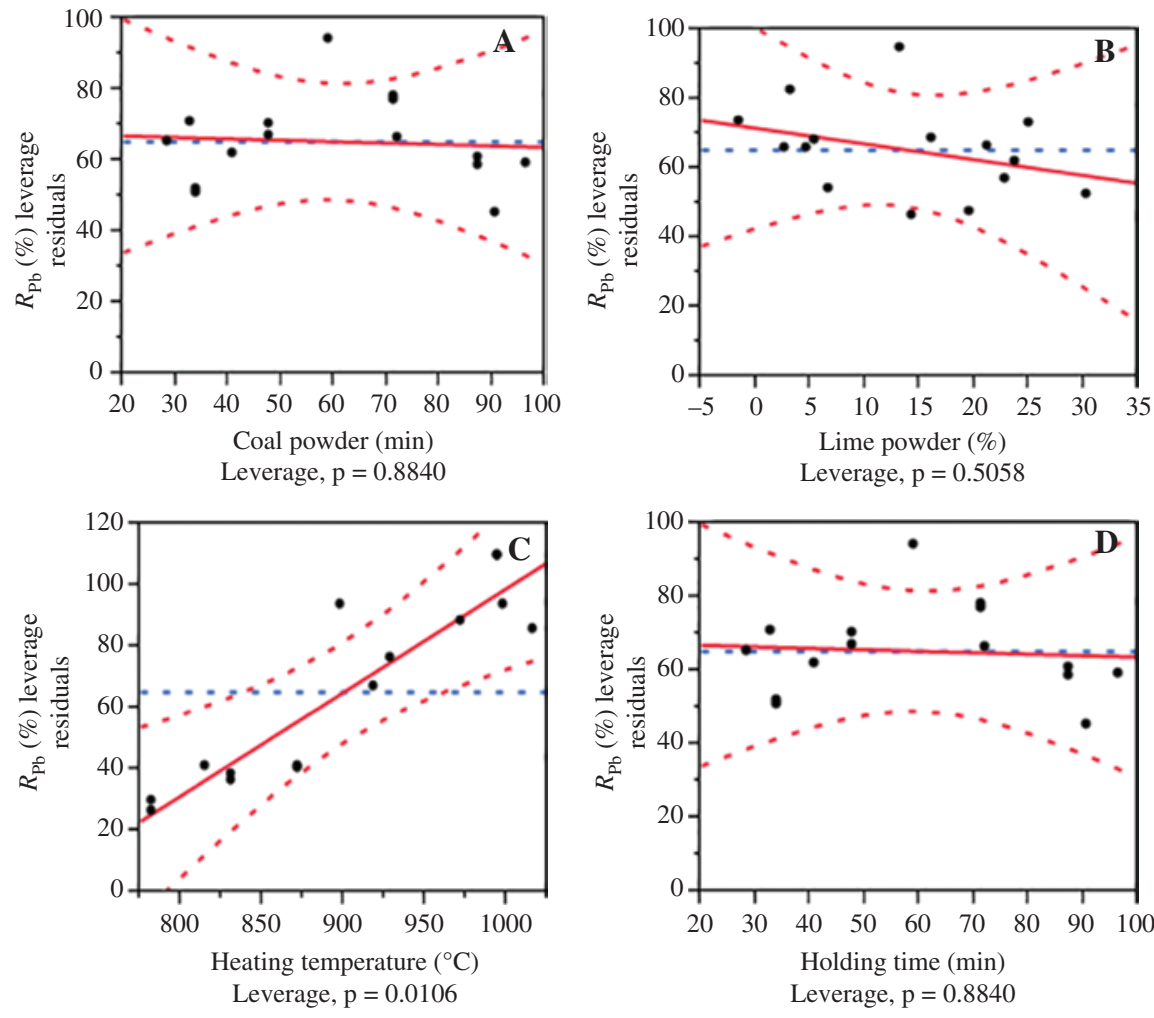

Figure 3: Leverage of the four factors for lead volatilization. 


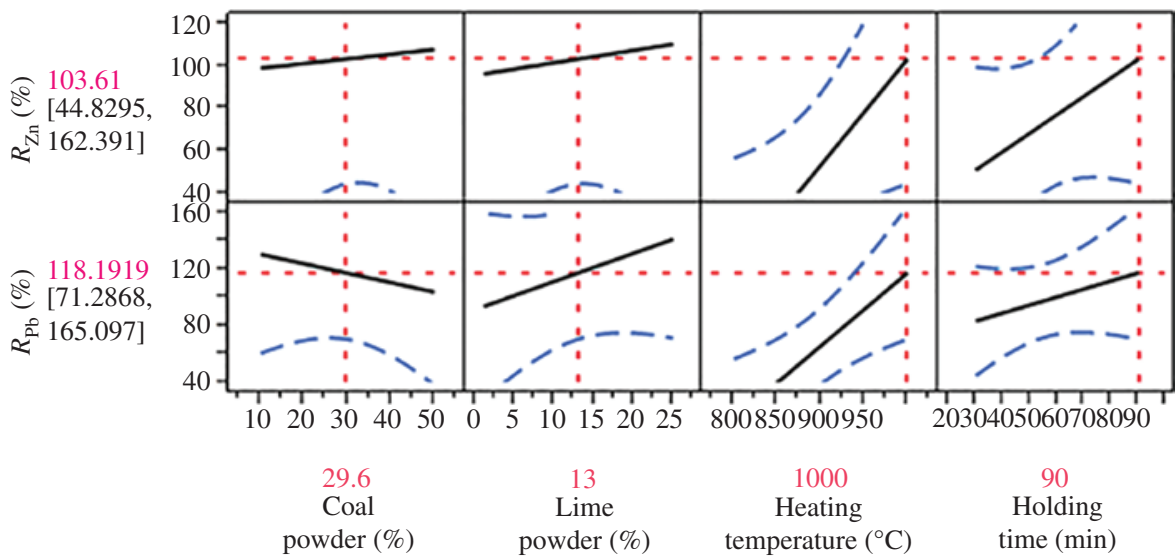

Figure 4: Fitting prediction of $\mathrm{Zn}$ and $\mathrm{Pb}$ volatilization from jarosite residues by vacuum reduction and distillation.

diagram is the regression line and the two dotted curves marked the confidence interval with $95 \%$ probability the same as in Figures 2 and 3. The dotted horizontal line represents zinc and lead volatilization ratios predicted by the software. It is seen in Figure 4 that increasing the amounts of coke and lime powder results in an increase in zinc volatilization ratio but the increase becomes smaller as the amounts of coke and lime powder increase. Increase in heating temperature and holding time significantly improves zinc volatilization. However, increase in coke powder results in a decrease in lead volatilization while increase in lime powder, heating temperature, and holding time leads to a significant increase in lead volatilization.

\subsubsection{Conditions optimization for zinc and lead volatilization}

As stated earlier, heating temperature is the most significant contributing factor to both zinc and lead volatilization. Thus, the most suitable heating temperature of the process is determined to be $1000^{\circ} \mathrm{C}$. In order to allow the two metals to fully volatilize, the most suitable holding time is found to be $90 \mathrm{~min}$. In Figure 4 it is seen that zinc almost fully volatilizes when the amounts of coke and lime powder are $29.6 \%$ and $13 \%$, respectively. Accordingly, lead volatilization is approximately at an optimum with the same amount of coke and lime powder. Therefore, addition of $29.6 \%$ coke powder and $13 \%$ lime powder to the residues, $1000^{\circ} \mathrm{C}$ heating temperature, and $90 \mathrm{~min}$ holding time are the optimal conditions for both zinc and lead volatilization. The experiment result showed that under the above optimal conditions zinc and lead volatilization ratios both reached $99.4 \%$.

\section{Conclusion}

The vacuum reduction and distillation process is an effective method for zinc and lead recovery from jarosite residues. Iron left in the slag is easy to recover by magnetic separation and convenient to be used. Thus, these three main metals, zinc, lead, and iron can be extracted from jarosite residues.

Among the conditions, heating temperature influences the recovery most significantly. This means that the control of heating temperature is the key operating parameter of this process.

The vacuum reduction and distillation avoids air pollution caused by the volatilization of lead and zinc providing a clean method in dealing with jarosite residues. It also provides a new idea in dealing with the hazardous waste which contains volatile metals such as zinc and lead.

\section{References}

[1] Ju SH, Zhang LB, Peng JH, Shi Z, Guo SH, Liu BG, Wang YJ. Trans. Nonferrous Met. Soc. China 2013, 23, 1179-1183.

[2] Liu Y, Tan J, Yin Z, Liu C, Chen Q, Zhang P, Liao Z, Wang X. Chin. J. Nonferrous Met. 2016, 26, 212-222.

[3] Han H, Sun W, Hu Y, Jia B, Tang H. J. Hazard. Mat. 2014, 278, 49-54.

[4] Xue P, Ju S, Zhang Y, Wang X. Chin. J. Process Eng. 2011, 11, 56-60.

[5] Jiang GH, Niu S, Liu J, Chen H. Hunan Nonferrous Met. 2013, 20-23.

[6] Yang H, Jiang B, Wang Y, Yuan X, Zhanh Y. Chin. J. Nonferrous Met. 2015, 250-257.

[7] Ning S, Chen Z. Chin. J. Nonferrous Met. 1997, 59-61.

[8] Shen Y, Tan S, Xiong Z. Nonferrous Metall. (Metall.) 2001, 33-35.

[9] Tang J, Huang J, Tian J. Chem. Indus. 2005, 19, 22-24.

[10] Huang J, Tang J, Chen S. Chin. J. Environ. Eng. 2007, 1, 134-138. 
[11] Fan L, Zen X, Xue P. Sci. Econ. Inner Mongolia 2012, 62-64.

[12] Wu W, Li S, Liao S, Wu X, Hou S, Meng X, Wang F. Chin. Nonferrous Met. 2009, 61, 71-75.

[13] Zou X, Chen T, Liu H, Chen D, Zhang P, Xie Q. J. Silic. 2013, 669-673.
[14] Lei X, Jiang L, Zhang S, Zhou R. Methods JMP Softw. 2014, 48-49.

[15] Liang B, Duan QH, Xu W, Zhu Y. Commercial Tech. Pet. 2009, 74-77.

[16] Li M, Peng B, Chai L, Peng N, Yan H, Hou D. J. Hazard. Mater. 2012, 237/238, 323-330. 